\title{
ADSORPTIVE MATERIALS BASED ON CELLULOSE: PREPARATION, CHARACTERIZATION AND APPLICATION FOR COPPER IONS RETENTION
}

\author{
IULIA NICA, ${ }^{*}$ CARMEN ZAHARIA, ${ }^{*}$ RALUCA IOANA BARON, ${ }^{* *}$ \\ SERGIU COSERI ${ }^{* *}$ and DANIELA SUTEU ${ }^{*}$ \\ "“Gheorghe Asachi” Technical University of Iasi, “Cristofor Simionescu” Faculty of Chemical Engineering \\ and Environment Protection, 73, D. Mangeron Blvd., 700050, Iasi, Romania \\ **" "Petru Poni" Institute of Macromolecular Chemistry of Romanian Academy, \\ 41A, Gr. Ghica Voda Alley, 700487, Iasi, Romania \\ 凶Corresponding authors: Daniela Suteu, danasuteu67@yahoo.com \\ Raluca Ioana Baron, baron.raluca@icmpp.ro
}

Received December 5, 2019

Hydrogels based on poly(vinyl alcohol) reticulated with TEMPO-oxidized cellulose (OxC25) are proposed as a highly convenient and effective adsorbent for retaining copper ions from aqueous solutions. The equilibrium of the adsorption process was described by the Langmuir model and the adsorption capacity at $20{ }^{\circ} \mathrm{C}$ was found to be $357.140 \mathrm{mg}$ of $\mathrm{Cu}^{2+} / \mathrm{g}$ of hydrogel. The value of the adsorption energy $(3.758 \mathrm{~kJ} / \mathrm{mol})$ less than $8 \mathrm{~kJ} / \mathrm{mol}$, obtained by processing the experimental results according to the Dubinin-Radushkevich isotherm, suggests that the retention of $\mathrm{Cu}^{2+}$ ions onto the OxC25 hydrogel may be due to relatively weak coordinative bonding, van der Waals forces, dipole-dipole interactions, and electrostatic interactions between the negatively charged surface of the hydrogel and the metal ions. The corresponding kinetic model suggests that the adsorption process proceeded in two controlled steps, beginning with film diffusion and followed by intraparticle diffusion.

Keywords: adsorbent, cellulose, copper ion, composite hydrogel, polluting species

\section{INTRODUCTION}

Cellulose represents a typical example of how natural polymers could be successfully implemented in our daily life as an omnipresent product, ranging from fibers, nano-scale components in electronic devices, microfibrils, paper, health and beauty care products, drugs, filters, and others. ${ }^{1-4}$ In the field of natural water resource protection and even its remediation, a lot of research has been done to develop naturalbased materials able to replace the synthetic ones, with better adsorption capability and easiness of reusing. ${ }^{5-9}$ Many attempts have been made to introduce a variety of natural cellulose and lignocellulosic materials as adsorbents for the retention of organic and/or inorganic polluting species from the aquatic environment. ${ }^{10-14}$ Cellulose as the most abundant natural polymer on the Earth fulfills such adsorptive requirements, being largely considered for such types of applications. ${ }^{10,15-17}$ To increase its versatility and avoid the complicated solvent systems needed for processing cellulose, often cellulose derivatisation is an elegant way to be considered. Among the multitude of synthetic routes for cellulose conversion, oxidation offers the advantage of highly stereospecific paths for conversion of the desired $\mathrm{OH}$ sites in the anhydro-glucose units of cellulose, with either $\mathrm{CHO}$ or $\mathrm{COOH}$ moieties. ${ }^{18-}$

A relatively new category of adsorptive materials is represented by hydrogels. They consist in structures of dense reticulated polymeric networks, which contain hydrophilic and hydrophobic fractions/parts in a defined proportion. The polymerization methods, the presence of functional groups and the nature of the reticulation agents are important parameters controlling the hydrogel swelling capacity. ${ }^{22}$ Due to a few certain advantages, such as the swelling capacity in water, hydrophilicity, biocompatibility 
and lack of toxicity, hydrogels are used in a wide range of sanitary, agricultural, medical and pharmaceutical applications, where their adsorption and retaining characteristics are essential. Moreover, hydrogels have recently received increasing interest in the area of wastewater treatment, due to their high adsorption capacity, ease of regeneration and possibility to be reused in continuous technological processes. ${ }^{22}$ It must be also underlined that pure hydrogels sometimes have certain limitations, such as low mechanical stability and resistance. That is why, different ways to surpass these inconveniences and to improve the required properties for various technological processes have been investigated. Thus, different methods of reticulation with helping agents (i.e. reticulation agents) have been applied and different types of composite hydrogels were obtained. ${ }^{22-24}$ For example, in an initial step of nanocomposite hydrogels development, different clay-based minerals were added, on a large scale, into matrices of polymeric hydrogels for improving their low mechanical stability. $^{22}$ A hydrogel can be chemically stable, or can be degraded and finally disintegrated and dissolved. ${ }^{23}$

Poly(vinyl alcohol) (PVA) represents a biodegradable polymer that has been used in recent years for manufacturing hybrid biodegradable materials, as a replacement of traditional polymers from polyethylene or polypropylene. These materials have been proved to have beneficial applications in water filtration, paper industry, or production of different coverings, films and packages. However, this polymer presents low mechanical resistance and therefore other components capable of improving this property are necessary. For this reason, it has been proposed to use different amounts of natural polymers (cellulose and pullulan), in the form of oxidized C6 derivatives, as key multifunctional components, which would be able to act as reticulation agents, but also as agents for increasing the strength and rigidity properties of some composite PVA hydrogels. ${ }^{26}$ Moreover, these hydrogels obtained from natural resources can be successfully used as adsorbents for retaining some chemical species of interest from different aqueous media. The use of hydrogels to obtain different commercial products with adsorptive properties (with diverse applications, inclusively in environmental protection and medicine) must be initially tested with reference to their action mechanism, principal influencing factors and environmental and health risks, as well as their performance in retaining some ionic or/and molecular species. A part of this information is useful in the optimization of the adsorption process (minimal or/and maximal adsorption capacity and performance in retaining the studied species) and, respectively, for the evaluation of the reverse process - the desorption, for potential controlled desorptions, which are of actual interest in the biomedical and agricultural fields, as well as for finding the most favorable factors for the development of this process under critical conditions, or under the most recommended ones.

The aim of this paper has been to evaluate the adsorptive properties of hydrogels obtained by introducing 6-carboxy cellulose, as a key component, into the matrix of poly(vinyl alcohol) (PVA), towards metallic ions (copper ions as representative model in this work). Before the adsorption experiments, the hydrogels were characterized using FTIR and SEM. The adsorption studies were focused on: (i) determining the most suitable adsorption isotherm; (ii) establishing certain thermodynamic adsorption parameters (the adsorption energy and maximum adsorption capacity of the tested composite hydrogels towards copper ions); (iii) determining a few kinetic adsorption parameters and the corresponding kinetic adsorption model, and (iv) identifying the most probable adsorption mechanism (especially, the adsorption controlled steps).

\section{EXPERIMENTAL \\ Materials}

Commercial poly(vinyl alcohol) (PVA), with an average molecular weight of $8.9 \times 10^{4}-9.8 \times 10^{4} \mathrm{~g} / \mathrm{mol}$, and $99 \%$ hydrolyzed and purified cellulose (microcrystalline, Avicel® PH 101), with a degree of polymerization (DP) of 135, were purchased from Sigma-Aldrich Co.

For cellulose oxidation, commercially available pure grade reagents (Sigma Aldrich Co.), i.e. 2,2,6,6tetramethyl-1-piperidinyloxy (TEMPO), sodium bromide and 9\% (wt) sodium hypochlorite, were used.

Metal ionic species: $\mathrm{Cu}^{2+}$ ions were selected as polluting inorganic species, presented as $\mathrm{CuSO}_{4} \mathrm{x}$ $5 \mathrm{H}_{2} \mathrm{O}$ (from Chemical Company, Romania) solution, and tested in the concentration range of $25-204 \mathrm{mg}$ of $\mathrm{Cu}^{2+} / \mathrm{L}$ of solution. The concentration of the stock solution was $635.76 \mathrm{mg} \mathrm{Cu}^{2+} / \mathrm{L}$. 
Methods

Methods used for physicochemical characterization of cellulosic adsorbents

For recording the Fourier transform infrared (FTIR) spectra, a Vertex 70 spectrometer was used, while for data processing, the OPUS 6.5 software was activated. All the spectra were recorded in the mid IR range (4000-600 $\mathrm{cm}^{-1}$ ).

For determining the samples' morphology, an Environmental Scanning 200 instrument (ESEM, Quanta 200, FEI Company, Hillsboro, OR, USA), operating at $5 \mathrm{kV}$ with secondary electrons in High Vacuum Mode, was used.

\section{Preparation of composite hydrogels}

Synthesis of 6-carboxy cellulose $(\mathrm{OxC})$

Avicel® PH 101 microcrystalline cellulose (10 g) was immersed in $600 \mathrm{~mL}$ of distilled water in a 3necked flask under vigorous stirring. Then, 2,2,6,6tetramethylpiperidine 1-oxyl (TEMPO) $(1 \mathrm{mmol} / \mathrm{g}$ cellulose) and sodium bromide $(\mathrm{NaBr})(10 \mathrm{mmol} / \mathrm{g}$ cellulose) were added. A solution of $\mathrm{NaCl}(8 \%$ active chlorine), corresponding to $20 \mathrm{mmol} / \mathrm{g}$ cellulose, was added to the slurry with a strict control of the $\mathrm{pH}$ value, which should be kept around 10 . The solution was maintained under vigorous stirring for 5 hours. After this, the reaction was stopped by adding a few drops of glycerol and the resulted mixture was filtered off. The supernatant was collected and precipitated using an excess of ethyl alcohol. The precipitate was separated, then redissolved in Millipore-based distilled water, following the purification procedure using dialysis (in a membrane with a pore size of 12.000 $\mathrm{g} / \mathrm{cm}$ ). Finally, the oxidized cellulose was recovered by lyophilization.

\section{Synthesis of composite hydrogels}

The oxidized cellulose $(0.21 \mathrm{~g})$ was dissolved in distilled water $(7 \mathrm{~mL})$ and left under stirring for 3 hours. A PVA solution, with the concentration of $3 \%$, was prepared by stirring powder PAV in distilled water, for achieving the dissolution of the former, at 70 ${ }^{\circ} \mathrm{C}$ for 10 hours. For preparing the composite hydrogels, these two solutions were mixed to a final OxC/PVA ratio $(\mathrm{w} / \mathrm{w})$ equal with $1 / 3$. The hydrogel networks were obtained after 3 cycles of freezing/thawing and thereafter drying by lyophilization. The thus obtained hydrogel was labeled as $\mathrm{OxC} 25$.

\section{Adsorption methodology}

Known volumes $(25 \mathrm{~mL})$ of $\mathrm{Cu}^{2+}$ solutions, with different initial concentrations (25.43-203.44 mg/L) and $\mathrm{pH}$ values of 1.6 adjusted with the help of $\mathrm{H}_{2} \mathrm{SO}_{4}$ $1 \mathrm{~N}$ solutions, were contacted with a well-established dose of adsorbent $(0.01 \mathrm{~g})$ for 24 hours, or for a certain time period $(\mathrm{t})$ at three temperatures of $5^{\circ}, 20^{\circ}$ and 35 ${ }^{\circ} \mathrm{C}$, respectively. The constant temperature for the adsorption process development was maintained using a Poleko SLW 53 thermostatic bath. The adsorption systems were subjected to discontinuous stirring. After 24 hours, when it was assumed that equilibrium was reached, or a certain contact time period $(t)$, the residual metallic ion $\left(\mathrm{Cu}^{2+}\right.$ ions $)$ concentrations in the aqueous medium were determined using a UV-VIS Digital Spectrophotometer, model S 104D /WPA, by reading the aqueous solution absorbance at the wavelength $\lambda=378 \mathrm{~nm}$, after sample treatment with $0.05 \%$ rubeanic acid in acetate buffer $(\mathrm{pH}=4.6) .^{27}$ Two most important quantitative adsorption characteristics were evaluated by means of the amount of adsorbed copper ions and, consequently, the adsorption capacity of the hydrogel (Eq. 1):

$\mathrm{q}_{\mathrm{t}}=\frac{\mathrm{C}_{0}-\mathrm{C}_{\mathrm{t}}}{\mathrm{m}} \cdot \mathrm{V}$ or $\mathrm{q}_{\mathrm{e}}=\frac{\mathrm{C}_{0}-\mathrm{C}_{\mathrm{e}}}{\mathrm{m}} \cdot \mathrm{V}$

and the removal percentage of metallic ion (Eq. 2):

$R_{t}, \%=\frac{\left(\mathrm{C}_{0}-C_{t}\right) \cdot 100}{C_{0}}$ or

$R_{e}, \%=\frac{\left(\mathrm{C}_{0}-C_{e}\right) \cdot 100}{C_{0}}$

where $C_{0}, C_{t}$ and $C_{e}$ are the initial, after $t$ time period of adsorption and/or equilibrium concentration of metallic ion in the aqueous medium $(\mathrm{mg} / \mathrm{L}), m$ is the amount of adsorbent ( $\mathrm{g}$ ) and $V$ is the volume of aqueous sample (L).

\section{RESULTS AND DISCUSSION}

Adsorbent characterization by Fourier Transform Infrared (FTIR) Spectroscopy

Figure 1 presents the spectra of the initial cellulose (C), oxidized cellulose (OxC), PVA and composite hydrogel (OxC25). The FTIR of $\mathrm{C}$ shows a typical cellulose spectrum, with representative peaks located as follows: a large absorption band between $3600-3100 \mathrm{~cm}^{-1}$ due to the hydrogen-bonded $\mathrm{OH}$ stretching, and a band at $2800 \mathrm{~cm}^{-1}$ assigned to the $\mathrm{CH}$ stretching mode. The band at $1640 \mathrm{~cm}^{-1}$ is attributed to the $\mathrm{OH}$ bending mode due to bound water. The other two peaks typical of cellulose are present at $1372 \mathrm{~cm}^{-1}$ and $915 \mathrm{~cm}^{-1}$. The first one is known as a "crystalline" absorption band and the second as an "amorphous" one. Also, a "fingerprint" of the cellulose chain located around $1050 \mathrm{~cm}^{-1}$ could be assigned to $\mathrm{C}-\mathrm{O}-\mathrm{C}$ vibration bands. In the spectrum of the oxidized cellulose $(\mathrm{OxC})$, the main changes are visible at $1611 \mathrm{~cm}^{-1}$, due to the vibration of $\mathrm{COO}^{-}$groups appearing after oxidation. As for PVA, the broad band observed between 3550 and $3200 \mathrm{~cm}^{-1}$ is associated with $\mathrm{O}-\mathrm{H}$ stretching from the intermolecular and intramolecular hydrogen bonds. The vibrational band observed between 2840 and $3000 \mathrm{~cm}^{-1}$ is the result of the $\mathrm{C}-\mathrm{H}$ stretching from the alkyl groups 
and the peaks between 1730 and $1680 \mathrm{~cm}^{-1}$ are due to the $\mathrm{C}=\mathrm{O}$. The FTIR spectrum of the OxC25 hydrogel shows all the specific vibrations of PVA: the band $(\mathrm{OH})$ at about $3300 \mathrm{~cm}^{-1}$. The specific cellulose vibrations, such as $\mathrm{v}_{\mathrm{as}}\left(\mathrm{COO}^{-}\right)$ around $1610 \mathrm{~cm}^{-1}$ and $v(\mathrm{CO})$ at $1059 \mathrm{~cm}^{-1}$, are either found in the same place in the OxC25 spectrum, or slightly displaced in comparison with those of pure OxC.

\section{Morphology of hydrogels}

Figure 2 shows the morphology of both starting materials used for the preparation of the OxC25 hydrogel samples. It can be observed the oxidized cellulose (OxC) has a completely different morphology from that of the initial cellulose (sample C). The fibril appearance of the sample $\mathrm{C}$ is totally changed after oxidation, the OxC sample exhibiting a highly defibrillated structure. The morphology of PVA is similar to that of $\mathrm{OxC}$, with a cloudy appearance. Finally, the OxC25 sample has visible porosity, with welldetermined pores, with sizes between 14 to 46 $\mu \mathrm{m}$, having uniform composition, which confirms the good compatibility of the initial components. This finding was somewhat expected due to the morphological similarity observed previously.

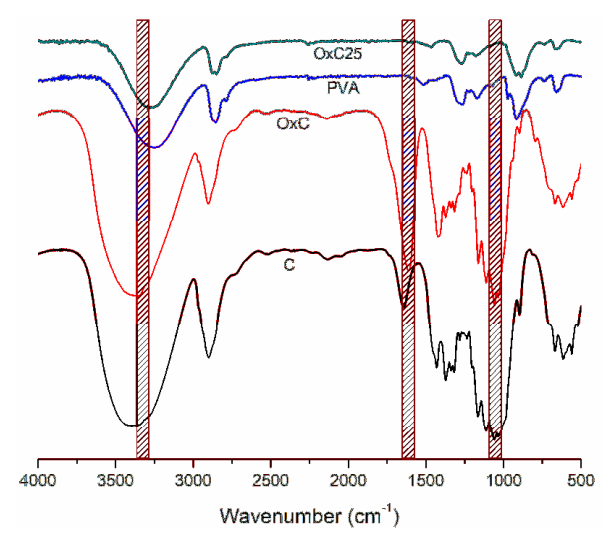

Figure 1: FTIR spectra of cellulose (C), oxidized cellulose (OxC), PVA and composite hydrogel (OxC25)
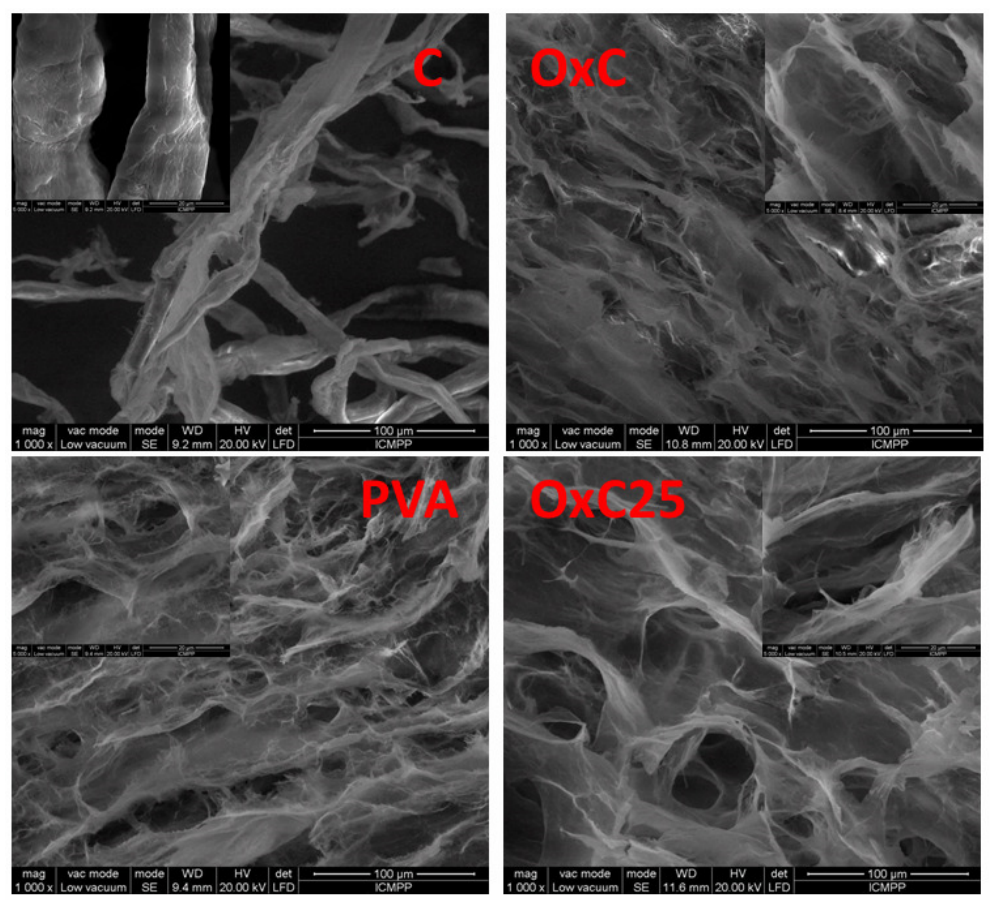

Figure 2: SEM microphotographs (1000x magnification) of cellulose (C), oxidized cellulose (OxC), PVA and composite hydrogel (OxC25); insets show SEM microphotographs at 5000x magnification 


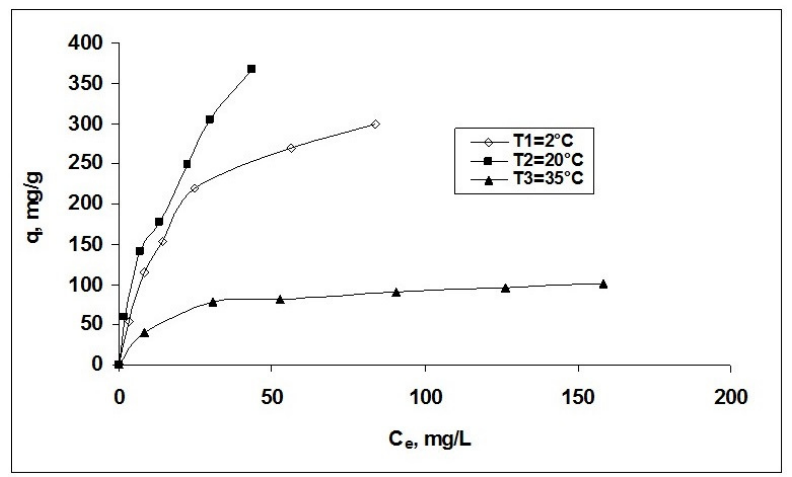

Figure 3: Isotherms of $\mathrm{Cu}^{2+}$ ion adsorption onto $\mathrm{OxC} 25$ hydrogel from aqueous medium (adsorbent dose of $0.4 \mathrm{~g} / \mathrm{L}$; contact time of $24 \mathrm{~h} ; \mathrm{pH}=1.6$ )

\section{Analysis of adsorption equilibrium}

A previous study $^{28}$ demonstrated that the OxC25 hydrogel exhibits the most attractive adsorbing properties vis-à-vis $\mathrm{Cu}^{+2}$ ions retention from aqueous media. For this reason, experimental research was performed considering this material as a working adsorbent. $\mathrm{OxC} 25$ is a composite PVA hydrogel, with $25 \%$ amount of incorporated cellulose-C as polysaccharide. Its main characteristic for the adsorption process is its pore size, which varies within the range of 14 and $46 \mu \mathrm{m}$.

The study of all the selected operating parameters: the $\mathrm{pH}$ of the aqueous metal ions solution, the dose of adsorbent and the contact time, revealed that the adsorption process of the copper ions proceeds optimally (meaning, with a high retention capacity), under the following conditions: $\mathrm{pH}=1.6$ achieved by using $1 \mathrm{~N} \mathrm{H}_{2} \mathrm{SO}_{4}$ solution, $0.4 \mathrm{~g} / \mathrm{L}$ of adsorbent and 24 hours of contact time..$^{28}$

The equilibrium of $\mathrm{Cu}^{2+}$ ions adsorption onto OxC25 hydrogel in aqueous solution was studied at $5^{\circ}, 20^{\circ}$ and $35^{\circ} \mathrm{C}$, using aqueous copper ion solutions with different initial concentrations, from 25.43 to $203.44 \mathrm{mg} / \mathrm{L}$. The adsorption isotherms are presented in Figure 3.

In order to model the relationship between the amount of copper ions adsorbed and the equilibrium concentration of the same metal ion, three of the most frequently used models: Freundlich, Langmuir and Dubinin-Radushkevich isotherms, have been considered.

The Freundlich isotherm, which assumes surface heterogeneity and exponential distribution of active adsorbent sites, uses the following general equation (Eq. 3) and its linearized form (Eq. 4): ${ }^{29}$

$$
\begin{aligned}
& \mathrm{q}=\mathrm{K}_{\mathrm{F}} \cdot \mathrm{C}^{1 / \mathrm{n}} \\
& \log \mathrm{q}=\log \mathrm{K}_{\mathrm{F}}+\frac{1}{\mathrm{n}} \log \mathrm{C}
\end{aligned}
$$

where $K_{F}\left((\mathrm{mg} / \mathrm{g})(\mathrm{L} / \mathrm{mg})^{1 / \mathrm{n}}\right)$ is a parameter related to the adsorption capacity and $n$ is a measure of adsorption intensity. The constants $K_{F}$ and $n$ are calculated from the graphical representation of the linearized equation (Eq. 4).

In accordance with the Langmuir model, there is a monolayer of adsorbate on the homogeneous surface of the adsorbent, which means that all the sites are equivalent and have the same adsorption enthalpy. There are two variants of the Langmuir model: L I and L II, having the following general equations (Eqs. 5-6): ${ }^{29}$

$$
\begin{aligned}
& \text { LI: } \frac{1}{q}=\frac{1}{q_{0}}+\frac{1}{K_{L} \cdot q_{0}} \cdot \frac{1}{C} \\
& \text { LII: } \frac{\mathrm{C}}{\mathrm{q}}=\frac{1}{\mathrm{q}_{0} \cdot \mathrm{K}_{\mathrm{L}}}+\frac{\mathrm{C}}{\mathrm{q}_{0}}
\end{aligned}
$$

The constants $K_{L}$ and $q_{0}$ were calculated from the plot of the linearized forms of the Langmuir equation I or II.

The Dubinin-Radushkevich (DR) model describes adsorption on microporous solids with a quasi-Gaussian distribution of adsorption enthalpy. This is defined by Equation $7:{ }^{29}$

$\ln q=\ln \mathrm{q}_{0}-\mathrm{B}^{2}$

where $q_{0}(\mathrm{mg} / \mathrm{g})$ is the maximum adsorption capacity, $B\left(\mathrm{~mol}^{2} / \mathrm{kJ}\right)$ is the activity coefficient related to mean adsorption energy and $\varepsilon$ is the Polanyi potential, equal to:

$\varepsilon=\mathrm{RT} \ln \left(1+\frac{1}{\mathrm{C}}\right)$

The adsorption energy, $\mathrm{E}(\mathrm{kJ} / \mathrm{mol})$, can be determined using the following equation: 


\section{IULIA NICA et al.}

$\mathrm{E}=\frac{1}{\sqrt{2 \mathrm{~B}}}$

The parameters related to each isotherm equation, calculated from the intercepts and slopes of the corresponding linear plots (Fig. 4 a, $\mathrm{b}$ and $\mathrm{c})$, together with their correlation coefficients $\left(R^{2}\right)$, are presented in Table 1 .
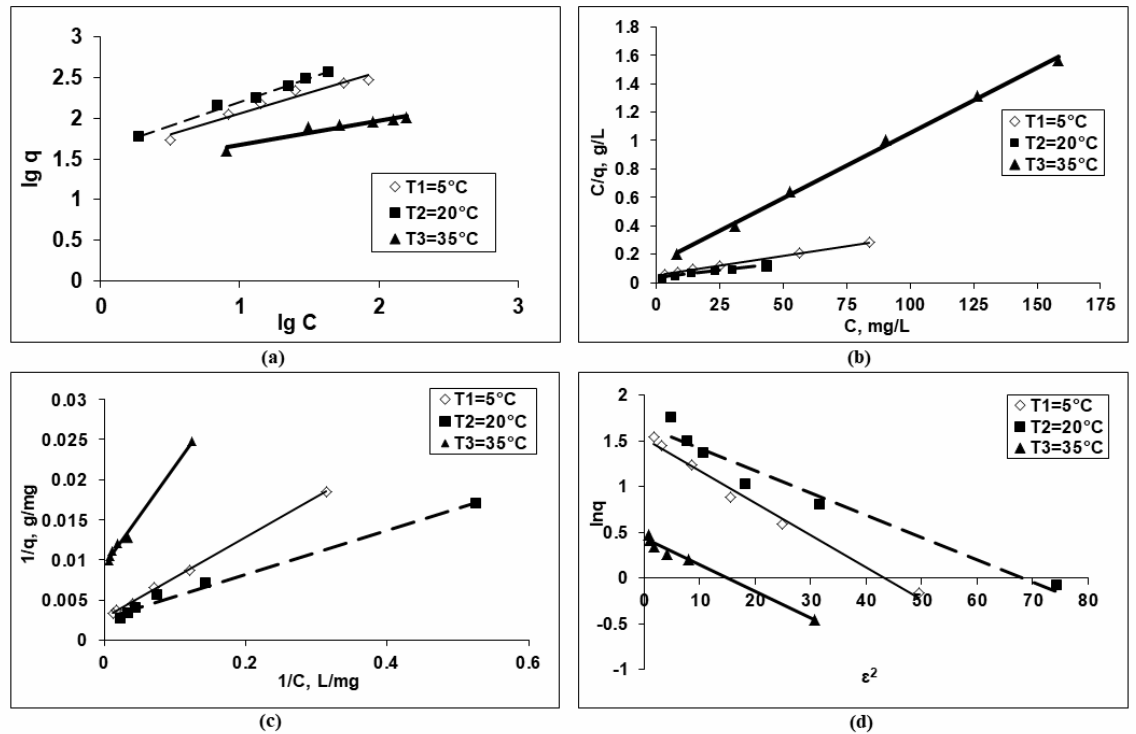

Figure 4: Freundlich (a), Langmuir I (b), Langmuir II (c) and DR (d) plots of adsorption isotherm for the retention of $\mathrm{Cu}^{2+}$ ions onto OxC25 hydrogel (adsorbent dose of $0.4 \mathrm{~g} / \mathrm{L} ; \mathrm{pH}=1.6$ ) at three temperatures

Table 1

Characteristic parameters of established isotherm equations

\begin{tabular}{|c|c|c|c|}
\hline \multirow{2}{*}{ Type of isotherm } & \multicolumn{3}{|c|}{$\mathrm{T}(\mathrm{K})$} \\
\hline & 278 & 293 & 308 \\
\hline \multicolumn{4}{|l|}{ Freundlich } \\
\hline $\mathrm{K}_{\mathrm{F}}\left((\mathrm{mg} / \mathrm{g})(\mathrm{L} / \mathrm{mg})^{1 / \mathrm{n}}\right)$ & 35.44 & 41.85 & 24.193 \\
\hline $\mathrm{n}$ & 1.946 & 1.728 & 3.395 \\
\hline $\mathrm{R}^{2}$ & 0.9522 & 0.9938 & 0.9202 \\
\hline \multicolumn{4}{|l|}{ Langmuir I $(\mathrm{C}=\mathrm{f}(\mathrm{C} / \mathrm{q}))$} \\
\hline $\mathrm{q}_{0}(\mathrm{mg} / \mathrm{g})$ & 357.143 & 500 & 108.696 \\
\hline $\mathrm{K}_{\mathrm{L}}(\mathrm{L} / \mathrm{g})$ & 0.056 & 0.0524 & 0.0673 \\
\hline $\mathrm{R}^{2}$ & 0.9988 & 0.9391 & 0.9974 \\
\hline \multicolumn{4}{|c|}{ Langmuir II $(1 / q=f(1 / C))$} \\
\hline $\mathrm{q}_{0}(\mathrm{mg} / \mathrm{g})$ & 357.143 & 357.14 & 106.383 \\
\hline $\mathrm{K}_{\mathrm{L}}(\mathrm{L} / \mathrm{g})$ & 0.05589 & 0.1022 & 0.076 \\
\hline $\mathrm{R}^{2}$ & 0.9994 & 0.9896 & 0.9956 \\
\hline \multicolumn{4}{|c|}{ Dubinin-Radushkevich (DR) } \\
\hline $\mathrm{q}_{0}(\mathrm{mg} / \mathrm{g})$ & 294.076 & 333.9996 & 97.880 \\
\hline $\mathrm{B}\left(\mathrm{mol}^{2} / \mathrm{kJ}\right)$ & 0.0354 & 0.0243 & 0.0291 \\
\hline $\mathrm{E}(\mathrm{kJ} / \mathrm{mol})$ & 3.7580 & 4.5360 & 4.1450 \\
\hline $\mathrm{R}^{2}$ & 0.9883 & 0.9548 & 0.9867 \\
\hline
\end{tabular}

Following the variation of all characteristic values of specific adsorption isotherm parameters calculated according to each considered model, a dependence relationship between the amount of retained copper ions and temperature has been found, the most significant values being attained 
in the range of $20-25{ }^{\circ} \mathrm{C}$. It is also observed from Table 1 that the adsorption process is best described by the Langmuir II model, according to the values of $R^{2}$. The adsorption energy values, calculated using the DR model, suggested that the adsorption process may be of the physical type, the adsorption energy $(3.7580 \mathrm{~kJ} / \mathrm{mol})$ being less than $8 \mathrm{~kJ} / \mathrm{mol}^{29,30}$ This suggests that $\mathrm{Cu}^{2+}$ ions binding onto the cellulosic material may be due to relatively weak coordinative bonding, van der Waals forces, dipole-dipole interactions, and electrostatic interactions between the negatively charged surface of the cellulose and the copper ions. The value of the adsorption capacity at 20 ${ }^{\circ} \mathrm{C}$ was found to be $357.14 \mathrm{mg}$ of $\mathrm{Cu}^{2+} / \mathrm{g}$ of hydrogel, in accordance with other data reported in the scientific literature for cellulosic materials used as adsorbents (Table 2). Also, the value of the adsorption capacity of the cellulosic adsorbents (OxC25 hydrogels) principally depends on the preparation technique and the existing functional groups, and then on the structure and properties of the studied metal ions (molecular weight, electronic structure, etc.), in this case, of copper ions (63.546; $3 \mathrm{~s}^{2} 3 \mathrm{~d}^{10} 3 \mathrm{p}^{6} 4 \mathrm{~s}^{1}$ (I-B, transitional chemical element)).

Also, it is observed that the value of the adsorption capacity decreases with increasing temperature to $35{ }^{\circ} \mathrm{C}$. This can be explained by the fact that accelerated diffusion due to increasing temperature does not automatically lead to better adsorption of copper ions, and a lower adsorption capacity may be caused by internal structure modification of the natural compounds (natural composite polymer degradation). The increase in the diffusion rate and the small size of copper ions lead to a series of hindrances and mutual controls of ions, finally conducing to a much more reduced adsorption. In this case, the use of the hydrogel for the retention of metal ion $\left(\mathrm{Cu}^{2+}\right)$ is preferred at a temperature of $20^{\circ} \mathrm{C}$.

Table 2

Comparison of $\mathrm{Cu}^{2+}$ adsorption performance of various cellulosic hydrogels used as adsorbents

\begin{tabular}{|c|c|c|}
\hline $\begin{array}{l}\text { Adsorbents based on celluloses } \\
\text { (as hydrogels) }\end{array}$ & $\begin{array}{c}\text { Adsorption capacity, }(\mathrm{mg} / \mathrm{g}) \\
\text { Conditions: initial concentration/sorbent } \\
\text { dose/pH/sorption time }\end{array}$ & Reference \\
\hline $\begin{array}{l}\text { Chitosan-cellulose hydrogel beads (chitosan } \\
\text { blended with cellulose to make chitosan- } \\
\text { cellulose hydrogel beads, which were crosslinked } \\
\text { with ethylene glycol diglycidyl ether (EGDE)) }\end{array}$ & $\begin{array}{c}53.2 \\
(5-100) \mathrm{mg} / \mathrm{L} / 0.1 \mathrm{~g} / 6 / 7 \text { days }\end{array}$ & 31 \\
\hline $\begin{array}{l}\text { WSC-g-PAA/PVA hydrogels (wheat straw } \\
\text { cellulose-g-poly(acrylic acid)/poly(vinyl alcohol) } \\
\text { hydrogels) }\end{array}$ & $\begin{array}{c}142.7 \\
(25-250) \mathrm{mg} / \mathrm{L} / 0.05 \mathrm{~g} /-/ 4 \mathrm{~h}\end{array}$ & 32 \\
\hline $\begin{array}{l}\text { CNFs-St-g-PAA hydrogels (cellulose nanofibers } \\
\text { (CNFs) treated with starch-g-poly(acrylic acid) } \\
\text { (St-g-PAA) superadsorbent hydrogels) }\end{array}$ & $\begin{array}{c}736 \text { (for untreated CNFs); } \\
957 \text { (for treated CNFs with St-g-PAA } \\
\text { hydrogels) } \\
(0.1-0.6) \mathrm{g} / \mathrm{L} / 0.03 \mathrm{~g} / 5 /-\end{array}$ & 33 \\
\hline $\begin{array}{l}C \text { - } g \text {-AA hydrogels (hydrogels based on cellulose- } \\
\text { graft-poly(acrylic acid) copolymers) }\end{array}$ & $\begin{array}{c}182 \\
<200 \mathrm{mg} / \mathrm{L} / 0.1 \mathrm{~g} / 7 /-\end{array}$ & 34 \\
\hline Graphene oxide/cellulose hydrogel & $\begin{array}{c}94.34 \\
-/ 0.01 \mathrm{~g} / \mathrm{L} / 5.3 / \text { ratio GO:Cell=20:100/- }\end{array}$ & 35 \\
\hline $\begin{array}{l}\text { OxC25 hydrogels (hydrogels based on poly(vinyl } \\
\text { alcohol) reticulated with cellulose) }\end{array}$ & $\begin{array}{c}357.14 \\
(25.43-203.4) \mathrm{mg} / \mathrm{L} / 0.01 \mathrm{~g} / 1.6 / 24 \mathrm{~h}\end{array}$ & $\begin{array}{l}\text { This } \\
\text { paper }\end{array}$ \\
\hline
\end{tabular}

\section{Kinetic modeling Influence of contact time}

One of the most important operating parameters of an adsorption process is the contact time between the two involved phases: liquid (aqueous metal ions medium) and solid (adsorbent), because it is extremely useful for characterization, modeling and optimization of the adsorption process. The effect of contact time 
on the adsorption of $\mathrm{Cu}^{2+}$ ions onto the $\mathrm{OxC} 25$ hydrogel is presented in Figure 5.

The graphical representation in Figure 5 shows that the values of the fractional attainment of equilibrium (F) increase rapidly with contact time during the first $500 \mathrm{~min}$ and, after that, the rate of metal ions adsorption slows down and the time period required for maximum removal and/or equilibrium establishment was found to last up to 24 hours. Also, the adsorption half-times $\left(t_{1 / 2}\right)$ were established up to $100 \mathrm{~min}$.

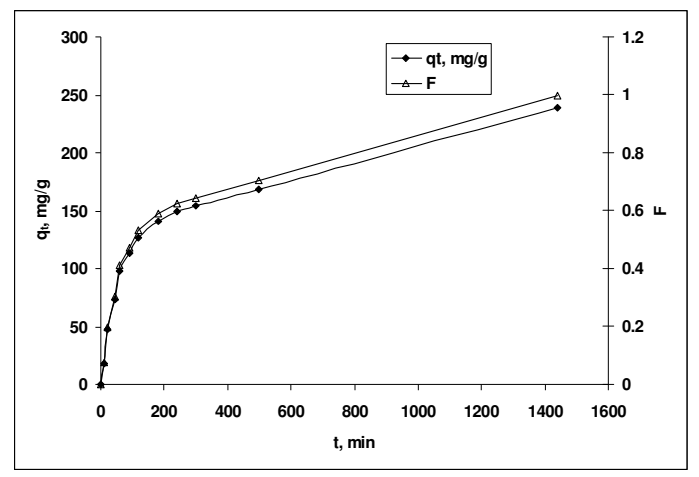

Figure 5: Influence of contact time on $\mathrm{Cu}^{2+}$ ions adsorption onto $\mathrm{OxC} 25$ hydrogel (adsorbent dose of $0.4 \mathrm{~g} / \mathrm{L} ; \mathrm{pH}=1.6$; temperature of $20^{\circ} \mathrm{C}$ )

\section{Kinetic modeling}

A great number of specialists consider that the adsorption process at the solid-liquid interface can be described by three major steps, of which the one that proceeds at the lowest speed will govern the adsorption kinetics: ${ }^{29,36}$

(1) the diffusion of the adsorbate molecules from the aqueous medium to the adsorbent surface through the boundary layer (namely film diffusion),

(2) the diffusion of adsorbate molecules from the surface into the pores of the solid particles (namely pore diffusion, or intraparticle diffusion),

(3) the interaction of the adsorbate with the active sites on the surface of the adsorbent.

Since the most important step in adsorption processes is the diffusion in the liquid film surrounding the adsorbent particles (external diffusion) and the diffusion in adsorbent particles (internal diffusion), in order to investigate the type of the adsorption mechanism involved in the adsorption of $\mathrm{Cu}^{2+}$ ions onto the studied hydrogelbased adsorbent (particle diffusion/film diffusion, or chemical interaction) and to establish the ratedetermining step of the adsorption process, the kinetic data were processed using some of the most frequently used kinetic models presented below: $: 29,37,38$
$>$ Pseudo-first order (Lagergren model) well-fitted for modeling kinetic data if the plot $l g$ $\left(q_{e^{-}} q_{t}\right)$ versus $t$ gives straight lines, which pass through the origin of the axes, and the $q_{e}$ exp values agree with the calculated $q_{e}$. Its general equations is:

$\frac{\mathrm{dq}_{\mathrm{t}}}{\mathrm{dt}}=\mathrm{k}_{1} \cdot\left(\mathrm{q}_{\mathrm{e}}-\mathrm{q}_{\mathrm{t}}\right)$

and its linearized form:

$\lg \left(\mathrm{q}_{\mathrm{e}}-\mathrm{q}_{\mathrm{t}}\right)=\lg \mathrm{q}_{\mathrm{e}}-\frac{\mathrm{k}_{1}}{2.303} \mathrm{t}$

where $k_{1}$ - rate constant of the pseudo-first order model, (1/min); $q_{t}$ and $q_{e}(\mathrm{mg} / \mathrm{g})$ - amounts of dye adsorbed at $t$ time and at equilibrium $(24 \mathrm{~h})$, respectively.

$>$ Pseudo-second order (Ho model) suggests that the adsorption processes can be controlled by chemical adsorption or chemosorption involving valence forces through sharing or exchange of electrons between the two phases involved, if a linearity of plots of $t / q_{t}$ versus $t$ can observed, and the calculated values of $q_{t}$ are much closer to the experimental values. The general equation and its linearized form are:

$\frac{\mathrm{dq}_{\mathrm{t}}}{\mathrm{dt}}=\mathrm{k}_{2} \cdot\left(\mathrm{q}_{\mathrm{e}}-\mathrm{q}_{\mathrm{t}}\right)^{2}$ 
$\frac{\mathrm{t}}{\mathrm{q}_{\mathrm{e}}}=\frac{1}{\mathrm{k}_{2} \cdot \mathrm{q}_{\mathrm{e}}^{2}}+\frac{1}{\mathrm{q}_{\mathrm{e}}} \mathrm{t}$

where $k_{2}$ - rate constant of the pseudo-second order model, $\mathrm{g} /(\mathrm{mg} \min ) ; k_{2} q_{e}^{2}=h-$ initial adsorption rate, $\mathrm{mg} /(\mathrm{g} \min )$.

$>$ Elovich model - is applied in adsorption systems with heterogeneous adsorbent surface. The studied processes can be described as chemical adsorption, if the representation $q_{t}$ versus $\ln t$ is linear and intersects the origin of the axes. The characteristic equation is:

$\mathrm{q}_{\mathrm{t}}=\frac{\ln (\alpha \cdot \beta)}{\beta}+\frac{1}{\beta} \ln \mathrm{t}$

where $\alpha-$ a constant referring to the initial adsorption rate $(\mathrm{mg} /(\mathrm{g} \min )) ; \beta-$ a constant referring to the extent of surface coverage, and activation energy for chemo-sorption $(\mathrm{g} / \mathrm{mg})$.

$>$ Intraparticle diffusion model (WebberMorris model) implies diffusion-controlled kinetics; pore diffusion is the rate-limiting step if the plot $q_{t} v s . t^{1 / 2}$ is linear and passes through the origin:

$\mathrm{q}_{\mathrm{t}}=\mathrm{k}_{\mathrm{d}} \cdot \mathrm{t}^{1 / 2}+\mathrm{c}$

where $k_{d}$ is the rate constant for intraparticle diffusion, $\mathrm{mg} /\left(\mathrm{g} \mathrm{min}^{1 / 2}\right) ; c$ - the intercept to $\mathrm{Y}$ axis.

$>\quad$ Film diffusion model (McKay model) film diffusion is involved in the adsorption process if the plot $\ln (1-F) v s . t$ is linear, and it is the rate-limiting step if the line passes through the origin.

$\ln (1-F)=\mathrm{k}_{f} t$

where $k_{f}$ is the rate constant for film diffusion, $1 / \mathrm{min} ; F$ - fractional attainment.

The characteristic kinetic parameters of each model, calculated from the intercepts and slopes of the corresponding linear plots (Fig. 6), are presented in Table 3. Using the values of the linear regression correlation coefficient, $\mathrm{R}^{2}$, the fit of each model to the experimental data was estimated.

The data presented in Table 3 and the graphical representation in Figure 6 suggest the following conclusions about the studied kinetics of the adsorption process:

- The plot $\ln \left(q_{e}-q_{t}\right)$ versus $t$ does not give a straight line and the $q_{e}$ values do not agree with the calculated $q_{e, \text { exp }}$, all of these suggesting that the pseudo-first order model is not suitable for modeling the kinetic data.

- The linearity of plots $t / q_{t}$ versus $t$, the calculated values of $q_{t}$ closer to the experimental value, and the highest values of the correlation coefficient, $R^{2}$, suggest that the adsorption kinetics of $\mathrm{Cu}^{2+}$ ions onto the OxC25 hydrogels follows a pseudo-second order kinetic model, and the adsorption process can be controlled by chemical adsorption, or chemo-sorption, involving valence forces through sharing or exchange of electrons between the two phases involved.

- The $R^{2}$ values greater than 0.95 for the studied adsorption system (in the case of relatively low concentrations) suggest that the data fit well the Elovich equation in this case, but because the linear representation $q_{t}$ versus $\ln t$ does not intersect the origin of the axes, chemosorption cannot be the only step that controlled the studied adsorption process, and the diffusion process remained the step that could control the adsorption.

Taking into account these three conclusions, it can be assumed that the adsorption rate can be governed by either liquid phase mass transport, or by intraparticle mass transport. Thus, in order to obtain more information about the diffusion mechanism, the kinetic results were analyzed by the intraparticle diffusion model (Webber-Morris model) (Fig. 7a) and the film diffusion model (McKay model) (Fig. 7b). ${ }^{29,39}$

As can be seen from Figure 7 (a), the experimental points (Webber-Morris model) are aligned along a straight line, thus intraparticle diffusion occurs; but because none passes through the origins, the assumption arises that both diffusion mechanisms (intraparticle and film diffusion) are involved in the adsorption processes, and might be the rate-determining step. The multi-linearity of the plots indicates that two or more steps controlled the adsorption process: ${ }^{29,39}$ (a) the first part could be regularly associated with film diffusion (external mass transfer) $;^{38}$ (b) the second linear part suggests intraparticle diffusion (into the porous structure of the adsorbent). ${ }^{40}$ The graphical representation of the McKay model (Fig. 7 b) proves that film diffusion is not involved in the adsorption process because the plot $\ln (1-F) v s . t$ is not linear, and it is not the rate-limiting step because the line does not pass through the origin. As a result, the ratelimiting step would be, in the first minutes, the mass transfer of $\mathrm{Cu}^{2+}$ ions at the external surface of OxC25 hydrogel, then associated with film diffusion and followed by intraparticle diffusion. 


\section{IULIA NICA et al.}

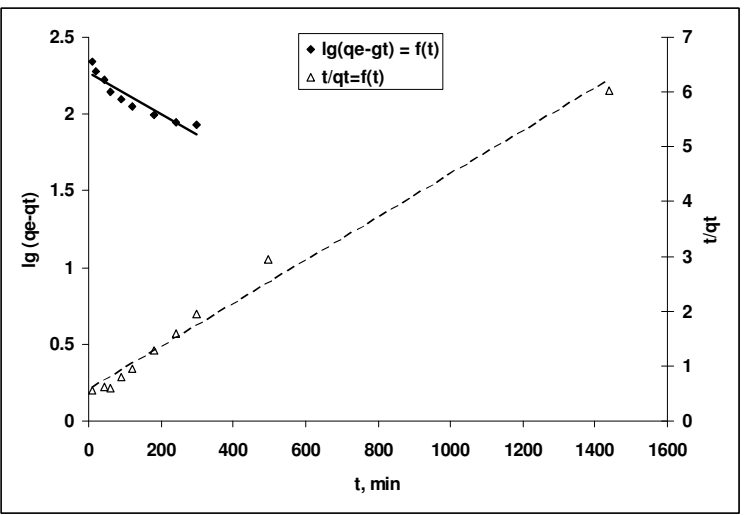

Figure 6: Applicability of pseudo-first order and pseudo-second order diffusion kinetic models to $\mathrm{Cu}^{2+}$ adsorption onto OxC25 hydrogel (adsorbent dose of $0.4 \mathrm{~g} / \mathrm{L}$; $\mathrm{pH}=1.6$; temperature of $20^{\circ} \mathrm{C}$ )

Table 3

Kinetic parameters for $\mathrm{Cu}^{2+}$ adsorption onto OxC25 hydrogel

\begin{tabular}{|c|c|c|c|c|c|c|c|c|c|c|c|c|c|}
\hline \multirow{3}{*}{$\begin{array}{c}\text { Kinetic } \\
\text { model }\end{array}$} & \multicolumn{3}{|c|}{ Pseudo first order kinetic } & \multicolumn{3}{|c|}{ Pseudo second order kinetic } & \multicolumn{3}{|c|}{ Elovich model } & \multicolumn{4}{|c|}{ Intra-particle diffusion } \\
\hline & $\begin{array}{c}\mathrm{k}_{1}, \\
(1 / \mathrm{min})\end{array}$ & $\begin{array}{c}\mathrm{q}_{\mathrm{e}} \\
(\mathrm{mg} / \mathrm{g})\end{array}$ & $\mathrm{R}^{2}$ & $\begin{array}{c}\mathrm{k}_{2}, \\
{[\mathrm{~g} /(\mathrm{mg} \min )]}\end{array}$ & $\begin{array}{c}\mathrm{q}_{\mathrm{e}} \\
(\mathrm{mg} / \mathrm{g})\end{array}$ & $\mathrm{R}^{2}$ & $\begin{array}{c}\alpha, \\
{[\mathrm{mg} /(\mathrm{g} \min )]}\end{array}$ & $\begin{array}{c}\beta, \\
(\mathrm{g} / \mathrm{mg})\end{array}$ & $\mathrm{R}^{2}$ & $\begin{array}{c}\mathrm{k}_{\mathrm{d} 1} \\
{\left[\mathrm{mg} /\left(\mathrm{g} \min ^{0.5}\right)\right]}\end{array}$ & $\begin{array}{c}\mathrm{k}_{\mathrm{d} 2} \\
{\left[\mathrm{mg} /\left(\mathrm{g} \min ^{0.5}\right)\right]}\end{array}$ & & \\
\hline & 0.0032 & 187.15 & 0.869 & $2.7 \times 10^{-5}$ & 256.41 & 0.986 & 6.783 & 0.025 & 0.987 & 16.35 & 4.37 & 0.977 & 0.979 \\
\hline $\mathrm{q}_{\mathrm{e}, \exp }(\mathrm{mg} / \mathrm{g})$ & & & & & & & 357.1 & & & & & & \\
\hline
\end{tabular}




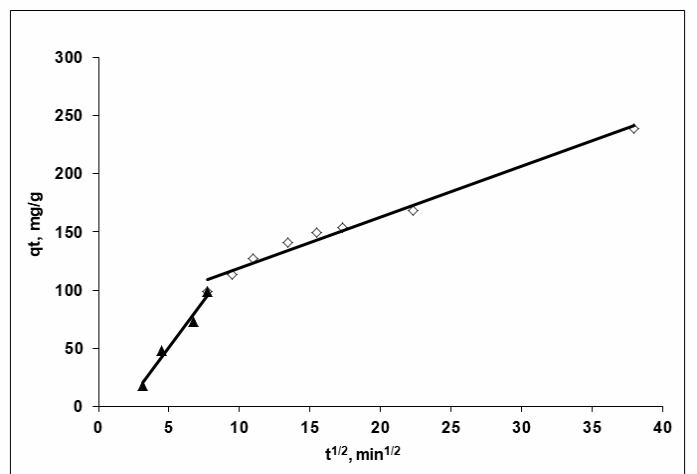

(a)

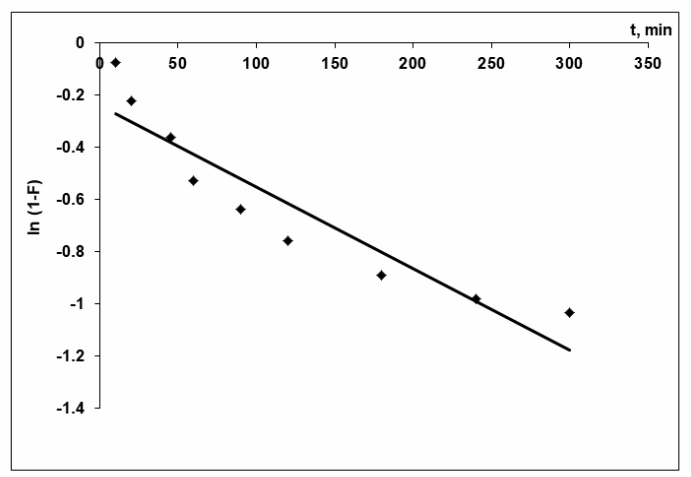

(b)

Figure 7: Applicability of intraparticle diffusion kinetic model (a) and film diffusion model (b) to $\mathrm{Cu}^{2+}$ ions adsorption onto OxC25 hydrogel (adsorbent dose of $0.4 \mathrm{~g} / \mathrm{L} ; \mathrm{pH}=1.6$; temperature of $20^{\circ} \mathrm{C}$ )

\section{CONCLUSION}

Hydrogels based on poly(vinyl alcohol) reticulated with cellulose can be considered as materials with efficient adsorptive properties, for the retention of copper ions from aqueous solutions, with moderate initial copper ion concentration. The equilibrium of the adsorption process is described by the Langmuir model (the value of adsorption capacity at $20{ }^{\circ} \mathrm{C}$ was found to be $357.14 \mathrm{mg}$ of $\mathrm{Cu}^{2+} / \mathrm{g}$ of hydrogel), as well as by processing the experimental results according to the Dubinin-Radushkevich isotherm (the process energy was less than $8 \mathrm{~kJ} / \mathrm{mol}$ ). This value of adsorption energy suggests that $\mathrm{Cu}^{2+}$ ions binding onto the hydrogel may be due to relatively weak coordinative bonding, van der Waals forces, dipole-dipole interactions, and electrostatic interactions between the negatively charged surface of the hydrogel and the metal $\left(\mathrm{Cu}^{2+}\right)$ ions.

The corresponding kinetic model suggests that this adsorption process was developed in two controlled steps, beginning with mass transfer film diffusion, and followed by intraparticle diffusion.

\section{REFERENCES}

1 N. Anghel, S. Lazar, B. I. Ciubotaru, L. Verestiuc and I. Spiridon, Cellulose Chem. Technol., 53, 879 (2019),

https://doi.org/10.35812/CelluloseChemTechnol.2019. 53.85

2 G. Biliuta, D. Suteu, T. Malutan, A. I. Chirculescu, I. Nica et al., Cellulose Chem. Technol., 52, 609 (2018),

http://www.cellulosechemtechnol.ro/pdf/CCT78(2018)/p.609-618.pdf
3 D. Rusu, D. Ciolacu and B. C. Simionescu, Cellulose Chem. Technol., 53, 907 (2019), https://doi.org/10.35812/CelluloseChemTechnol.2019. 53.88

4 A. R. Nair, S. Sambhudevan and B. Shankar, Cellulose Chem. Technol., 53, 263 (2019), https://doi.org/10.35812/CelluloseChemTechnol.2019. 53.26

5 G. Z. Kyzas and M. Kostoglon, Materials, 7, 333 (2014), https://doi.org/10.3390/ma7010333

6 T. T. C. Truong, N. T. T. Vo, K. D. Nguyen and H. M. Bui, Cellulose Chem. Technol., 53, 573 (2019), https://doi.org/10.35812/CelluloseChemTechnol.2019. 53.57

7 B. O. Opeolu, O. Bamgbose, T. A. Arowolo and M. T. Adetunji, Sci. Res. Essays, 5, 1780 (2010), https://academicjournals.org/journal/SRE

8 G. Z. Kyzas, J. Fu and K. A. Matis, Materials, 6, 5131 (2013), https://doi.org/10.3390/ma6115131

9 C. Zaharia and D. Suteu, in "Organic Pollutants Ten Years After the Stockholm Convention Environmental and Analytical Update", edited by T. Puzyn and A. Mostrag-Szlichtyng, InTech, 2012, Chapter 3, https://doi.org/10.5772/32373

10 A. Bajpai and N. Tripathi, Procedia Eng., 75, 56 (2014), https://doi.org/10.1016/j.proeng.2013.11.011

11 G. Crini, Prog. Polym. Sci., 30, 38 (2005), https://doi.org/10.1016/j.progpolymsci.2004.11.002

12 D. Suteu, C. Zaharia and T. Malutan, in "Lignin. Properties and Applications in Biotechnology and Bioenergy", edited by R. J. Paterson, Nova Science Publishers Inc., 2012, pp. 279-305, https://novapublishers.com/shop/lignin-properties-andapplications-in-biotechnology-and-bioenergy/

${ }^{13}$ A. O. Ifelebuegu and A. Johnson, Crit. Rev. Env. Sci. Technol., 47, 964 (2017), https://doi.org/10.1080/10643389.2017.1318620

14 S. Moosavi, S. Gan and S. Zakaria, Cellulose Chem. Technol., 53, $815 \quad$ (2019), https://doi.org/10.35812/CelluloseChemTechnol.2019. 53.80 


\section{IULIA NICA et al.}

15 F. C. Silva, L. C. B. Lima, R. D. S. Bezerra, J. A. Osajima and E. C. Silva Fieho, in "Cellulose Fundamental Aspects and Current Trends", edited by M. Poletto, H. Luiz and Ornaghi Jr., InTech, 2015, Chapter 5, https://doi.org/10.5772/61343

16 D. W. O'Connell, C. Birkinshaw and T. F. O'Dwyer, Bioresour. Technol., 99, 6709 (2008), https://doi.org/10.1016/j.biortech.2008.01.036

17 S. Olivera, H. B. Muralidhara, K. Venkatesh, V. K. Guna, K. Gopalakrishna et al., Carbohyd. Polym., 153, 600 (2016),

https://doi.org/10.1016/j.carbpol.2016.08.017

18 A. E. J. De Nooy, A. C. Besemer and H. van Bekkum, Carbohyd. Res., 269, 89 (1995), https://doi.org/10.1016/0040-4020(95)00417-7

19 T. Isogai, T. Saito and A. Isogai, Biomacromolecules, 11, $1593 \quad$ (2010), https://doi.org/10.1021/bm1002575

${ }^{20}$ H. Hondo, T. Saito and A. Isogai, Cellulose, 26, 3021 (2019), https://doi.org/10.1007/s10570-01902311-5

21 Y. Okita, T. Saito and A. Isogai, Biomacromolecules, 11, $1696 \quad$ (2010), https://doi.org/10.1021/bm100214b

22 M. Kurecic and M. S. Smole, in "Nanocomposites - New Trends and Developments" edited by F. Ebrahimi, InTech, 2012, Chapter 7, http://dx.doi.org/10.5772/51055

23 F. Ullah, M. B. Othman, F. Javed, Z. Ahmad and H. M. Akil, Mater. Sci. Eng., C, 57, 414 (2015), https://doi.org/10.1016/j.msec.2015.07.053

${ }_{24}$ K. Varaprasad, G. M. Raghavendra, T. Jayaramudu, M. M. Yallapu and R. E. Sadiku, Mater. Sci. Eng., C, 79, 958

(2017), https://doi.org/10.1016/j.msec.2017.05.096

25 N. Masruchin, B. D. Park and V. N. Causin, Cellulose Chem. Technol., 51, 497 (2017), http://www.cellulosechemtechnol.ro/index.php

26 R. I. Baron, M. Bercea, M. Avadanei, G. Lisa, G. Biliuta et al., Int. J. Biol. Macromol., 123, 744 (2019), https://doi.org/10.1016/j.ijbiomac.2018.11.107

27 V. Fornea, S. Trupina, A. V. Iosub and L. Bulgariu, Bull. Inst. Polit. Iasi (Romania), 62, 9 (2017), http://www.bulipi-eee.tuiasi.ro/index.html

28 I. Nica, C. Zaharia, R. E. Tataru Farmus, R. I. Baron, S. Coseri et al., Bull. Inst. Polit. Iasi (Romania), 65, 69 (2019), http://www.bulipieee.tuiasi.ro/index.html

29 G. Crini and P. M. Badot, Prog. Polym. Sci., 33, 399

(2008),

https://doi.org/10.1016/j.progpolymsci.2007.11.001
30 K. Y. Foo and B. H. Hameed, Chem. Eng. J., 156, 2 (2010), https://doi.org/10.1016/j.cej.2009.09.013

31 N. Li and R. Bai, Sep. Purif. Technol., 42, 237 (2005), https://doi.org/10.1016/j.seppur.2004.08.002

32 J. Ding, Q. Li, X. Xu, X. Zhang, Y. Su et al., Carbohyd. Polym., 190, $12 \quad$ (2018), https://doi.org/10.1016/j.carbpol.2018.02.032

33 N. B. Baghbadorani, T. Behzad, N. Etesami and P. Heidarian, Composites Part B, 176, 107084 (2019), https://doi.org/10.1016/j.compositesb.2019.107084

34 S. Yang, S. Fu, J. Liu and Y. Zhou, J. Macromol. Sci. Part B Phys., 55, 722 (2016), https://doi.org/10.1080/00222348.2016.1179090

${ }_{35}$ X. Chen, S. Zhou, L. Zhang, T. You and F. Xu, Materials, $\quad 9, \quad 582 \quad$ (2016), https://doi.org/10.3390/ma9070582

36 D. K. Mahmoud, M. A. M. Salleh and W. A. W. A. Karim, J. Purit. Util. React. Environ. (PURE), 1, 451 (2012), http://www.sign-ificance.co.uk/index.php/PURE

37 S. Chowdhury and P. Saha, Clean-Soil Air Water, 39, 274

(2011), https://doi.org/10.1002/clen.201000170

38 G. M. Walker, L. Hansen, J. A. Hanna and S. J. Allen, Water Res., 37, 2081 (2003), https://doi.org/10.1016/S0043-1354(02)00540-7

39 K. M. Doke and E. M. Khan, Rev. Environ. Sci. Biotechnol., $\quad$ 12, 25 (2013), https://doi.org/10.1007/s11157-012-9273-z

40 V. C. Srivastava, M. M. Swamy, I. D. Mall, B. Prasad and I. M. Mishra, Colloid. Surfaces, A, 272, 89 (2006), https://doi.org/10.1016/j.colsurfa.2005.07.016 